\title{
O ENSINO DE HISTÓRIA E O USO DE REALIDADE AUMENTADA
}

\author{
HISTORY TEACHING AND THE USE OF AUGNENTED REALITY
}

ENSEÑANZA DE LA HISTORIA Y USO DE LA REALIDAD AUMENTADA

\begin{abstract}
Hugo Leonardo Pereira Rufino
Doutor em ciências pela Universidade Federal de Uberlândia (UFU). Professor e pesquisador do Instituto

Federal do Triângulo Mineiro (IFTM).

E-mail: hugo@iftm.edu.br.

Orcid: https://orcid.org/0000-0001-7687-3375

Luiz Gustavo Pereira da Silva

Mestrando em educação profissional tecnológica pelo Instituto Federal do Triângulo Mineiro (IFTM).

E-mail: gustavonettie@yahoo.com.br.

Orcid: https://orcid.org/0000-0003-3101-5363
\end{abstract}

\begin{abstract}
RESUMO
A realidade aumentada é uma tecnologia digital que complementa o mundo real através da inserção de elementos digitais, melhorando assim a experiência do usuário. Essas informações adicionais podem ser imagens em 3 dimensões, vídeos, sons ou animações. Essa tecnologia necessita de um dispositivo eletrônico para capturar o mundo real e misturá-lo as informações digitais, sendo muito favorecida pelo desenvolvimento de smartphones e tablets. Várias áreas do conhecimento vem estudando a realidade aumentada para compreenderem como podem se beneficiar de suas características e entre elas se destaca a educação. Esse estudo buscou através de uma revisão bibliográfica compreender as iniciativas nessa área com foco em seus benefícios e desafios. Dentre as diversas disciplinas, esta revisão focou em trabalhos voltados a de História, que por trabalhar com objetos históricos por vezes distantes pode ser favorecida pela realidade aumentada. Por meio dos trabalhos analisados nessa área em todo o mundo, constatamos que o emprego da realidade aumentada melhora a aprendizagem e contribui para um aumento da motivação intrínseca do aluno.
\end{abstract}

Palavras-chave: Tecnologia digital. Educação. Virtualização.

\section{ABSTRACT}

Augmented reality is a digital technology that complements the real world by inserting digital elements, thus improving the user experience. This additional information can be images in 3 dimensions, videos, sounds or animations. This technology requires an electronic device to capture the real world and mix it with digital information, being greatly favored by the development of smartphones and tablets. Several areas of knowledge have been studying augmented reality to understand how they can benefit from its characteristics and education stands out among them. This study sought through a bibliographic review to understand the initiatives in this area with a focus on its benefits and challenges. Among the various disciplines, this review focused on works focused on History, which by working with historical objects that are sometimes distant can be favored by augmented reality. Through the work analyzed in this area worldwide, we found that the use of augmented reality improves learning and contributes to an increase in the student's intrinsic motivation.

Keywords: Digital technology. Education. Virtualization. 


\section{RESUMEN}

La realidad aumentada es una tecnología digital que complementa el mundo real insertando elementos digitales, mejorando así la experiencia del usuario. Esta información adicional puede ser imágenes en 3 dimensiones, videos, sonidos o animaciones. Esta tecnología requiere un dispositivo electrónico para capturar el mundo real y mezclarlo con información digital, siendo muy favorecido por el desarrollo de teléfonos inteligentes y tabletas. Varias áreas del conocimiento han estado estudiando la realidad aumentada para comprender cómo pueden beneficiarse de sus características y entre ellas destaca la educación. Este estudio buscó a través de una revisión bibliográfica comprender las iniciativas en esta área con un enfoque en sus beneficios y desafíos. Entre las diversas disciplinas, esta revisión se centró en trabajos centrados en la Historia, que al trabajar con objetos históricos, en ocasiones distantes, pueden verse favorecidos por la realidad aumentada. A través del trabajo analizado en esta área a nivel mundial, encontramos que el uso de la realidad aumentada mejora el aprendizaje y contribuye a incrementar la motivación intrínseca del alumno.

Palabras-clave: Tecnología digital. Educación. Virtualización.

\section{INTRODUÇÃO}

Com a evolução das Tecnologias de Informação e Comunicação (TIC), o ato de ensinar torna-se cada vez mais desafiador, pois a educação não deve permanecer à margem dessa mudança, mas sua absorção deve primar por um uso efetivo dos recursos e não apenas de maneira alegórica. As TIC estão cada vez mais presentes na vida humana. $E$ no meio escolar não pode ser diferente, pois as utilizações dos recursos das TIC pelos professores estão crescendo na prática pedagógica e tornando-se um meio no processo de ensino e aprendizagem mais significativo (Martins, 2017). Compreender esse estado de mundo posto e como ele interfere no processo ensino-aprendizagem é fundamental. Mercado (2002) diz que as novas tecnologias, se bem utilizadas por professores capacitados, irão abrir um novo mundo de oportunidades educativas. Tezani (2011) diz que:

O uso das TIC na educação escolar possibilita ao professor e ao aluno o desenvolvimento de competências e habilidades pessoais que abrangem desde ações de comunicação, agilidades, busca de informações, até a autonomia individual, ampliando suas possibilidades de inserções na sociedade da informação e do conhecimento (Tezani, 2011, p.36).

Esse novo cenário, de pensar o processo educativo na perspectiva das TIC, é posto diante de todos os níveis de ensino, mas, de forma particular, sobre os adolescentes. Nessa fase, diferente da infância, os alunos já possuem acesso às TIC de forma ampla. Dados do Instituto Brasileiro de Geografia e Estatística - IBGE na Pesquisa Nacional por Amostra de Domicílios Contínua - PNAD Contínua, referente ao quarto trimestre de 2017, indicam que 
84,9\% das pessoas entre 14 e 17 anos utilizam a internet e que, nessa mesma faixa etária, 71,2\% possuíam celular em 2017 (IBGE, 2018).

Diversas iniciativas de novas abordagens de ensino vêm sendo empregadas, tendo em vista o crescimento significativo do uso de metodologias ativas, que podem ser vistas como "modelos mais centrados em aprender ativamente com problemas, desafios relevantes, jogos, atividades e leituras, combinando tempos individuais e tempos coletivos; projetos pessoais e projetos de grupo" (Morán, 2015, p. 19). Cada vez mais educadores se apoiam nas TIC para buscarem novas formas de mediação do processo ensinoaprendizagem, dentre as quais podemos destacar, mais recentemente, a tecnologia de Realidade Aumentada (RA).

Conforme Mendonça (2018) a RA consiste na possibilidade de associar um elemento digital, uma imagem, um vídeo ou mesmo um áudio a uma imagem real. Assim, a partir de uma imagem focalizada com a câmera de um dispositivo móvel, é possível estabelecer um vínculo com outro elemento, digital, que amplia aquela realidade. "Realidade aumentada é um conceito, muito mais do que tecnologia, relacionado à sobreposição de elementos virtuais e reais, alinhados em um mesmo espaço tridimensional, com os quais se pode interagir em tempo real" (Tori, 2010).

Essa possibilidade fornecida pela RA de interação com objetos virtuais sobre o mundo real traz inúmeras possibilidades de exploração na área de educação. O educador pode enriquecer sua exposição com modelos em três dimensões muito mais ricos em detalhes do que os modelos tradicionais vistos nos livros didáticos em duas dimensões. Além disso, o aluno tem a possibilidade de entender melhor os conceitos sem a necessidade de simples abstrações. Um exemplo interessante é a utilização de RA para a visualização de formas geométricas no estudo matemático que permite ao discente visualizar triângulos, losangos ou polígonos, por exemplo. Segundo Duval (1993) só é possível aprender matemática através da utilização das representações semióticas do objeto matemático, tornando representações mentais visíveis e acessíveis.

Mas a RA vai muito além da representação de objetos. Azuma et al. (2001) diz que ela pode ser aplicada a todos os sentidos, incluindo audição, toque e olfato. Além de fornecer interações prontas, essa tecnologia também permite ao estudante uma maior interação com os conteúdos, em um processo no qual eles próprios sejam os produtores 
de conteúdo nas aulas que podem ser compartilhados, sendo, assim, agentes ativos na dinâmica de aprendizagem.

A inserção de novas tecnologias na educação nem sempre ocorre de forma fácil, afinal, não se trata apenas de uma aplicação mecânica, mas sim, uma integração real onde o recurso não se apresente apenas como um enfeite, mas para preenchimento de lacunas no processo de ensino-aprendizagem e para aproximação do estudante com o objeto de estudo, sua realidade e sua capacidade de ação para modificação desta mesma realidade.

"O emprego da tecnologia associado a revisões dos métodos pedagógicos, da relação de ensino-aprendizagem, insere-se em um contexto ampliado, no qual, quem sabe mais, tem melhor formação, melhores oportunidades de vida. Por conseguinte, a inserção das tecnologias em sala de aula torna-se uma estratégia que aproxima o discente da realidade, uma vez que elas fazem parte do contexto social, cumprindo um movimento de socialização e compartilhamento da produção de conhecimentos." (Santos; Alves; De Magalhães Porto, 2018, p. 46)

Nesse contexto, essa pesquisa focará o emprego da RA como ferramenta pedagógica de apoio a aprendizagem, e dentre as diversas disciplinas que compõem os cursos, história foi a escolhida, pois segundo Costa e Cruz (2015), a aprendizagem de conteúdos programáticos em História passa, muitas vezes, pela necessidade de abstração e de imaginação de determinado modelo bidimensional, típico dos livros, em um formato tridimensional. No caso de processos de ensino-aprendizagem, torna-se importante que os recursos tradicionais como o manual, a projeção multimídia, etc., sejam complementados com ferramentas que permitam aos alunos um auxílio nessa abstração, proporcionandoIhes a visualização de um mesmo conteúdo em 3D.

A relevância desta pesquisa se dá pela necessidade constante de reflexão sobre o uso de novas tecnologias na educação. Buscaremos por meio de uma revisão bibliográfica avaliar os riscos e oportunidades deste conceito emergente que é a RA quando ele é empregado no ensino da disciplina de História.

Para alcançar nosso objetivo, esse artigo está dividido em 4 seções. Na primeira são definidos os aspectos metodológicos empregados nessa pesquisa, no segundo é apresentado os conceitos que norteiam a tecnologia de RA. Na terceira seção discutimos sobre os aspectos da disciplina de História e sua relevância na formação do indivíduo, no quarto são apresentados trabalhos em RA aplicados a História onde analisamos seus resultados. Por fim são apresentadas as considerações finais. 


\section{Aspectos metodológicos}

O trabalho desenvolvido foi uma revisão bibliográfica buscando informações sobre o tema proposto nas bases de dados científicas Capes, Scielo, Science direct, Scopus, IEEE e Google Acadêmico. A revisão bibliográfica é o primeiro passo para a construção de conhecimento científico. Por meio desse processo é que se encontram lacunas e oportunidades para novas teorizações e pesquisas empíricas. (Botelho, Cunha \& Macedo, 2011)

Foram selecionados diversos trabalhos científicos e publicações que apresentaram pontos fundamentais para compreensão sobre a RA no meio educacional especificamente na área de História, sendo os trabalhos concentrados em sua maioria nos últimos cinco anos. Gil (2002) aponta que pesquisas com propostas de análise das diversas posições acerca de um problema, na maioria dos casos são realizadas mediante fontes bibliográficas, exclusivamente.

Foram pesquisados vários estudos em língua portuguesa, espanhola e inglesa para elucidar de forma completa como a RA funciona, assim como sua utilização pelas instituições de ensino em História e suas possíveis aplicações em um futuro próximo, para melhoria da qualidade do processo de ensino e aprendizagem. Os descritores utilizados para esta pesquisa foram “Realidade Aumentada”, “História”, “Ensino” e “Educação”, bem como suas traduções para o idioma inglês e espanhol.

Após o levantamento preliminar foram excluídos aqueles documentos retornados que não atendiam aos critérios estabelecidos, sendo eles, o trabalho ter sido voltado ao ensino de História, o documento ter sido disponibilizado integralmente e não estar duplicado em outra base, a pesquisa apresentar análise de resultados e por fim o estudo não ter sido direcionado ao público infantil ou apenas para esse.

A seguir são apresentados os resultados da análise desses documentos.

\section{A realidade aumentada}

Vivemos em um mundo real onde constantemente utilizamos o mundo virtual e os interpretamos como partes distintas, mas e se ao contrário de estarem separados eles 
estivessem fundidos, entrelaçados em si mesmos? Esta é a proposta da RA, que enriquece o mundo real com elementos do mundo virtual. Azuma et al. (2001) diz que:

Um sistema de RA complementa o mundo real com objetos virtuais (gerados por computador) que parecem coexistir em um mesmo espaço no mundo real. Enquanto muitos pesquisadores ampliam a definição de RA além dessa visão, nós definimos que um sistema de RA deve ter as seguintes propriedades: combina objetos reais e virtuais em um ambiente real, roda interativamente e em tempo real, e registra (alinha) objetos reais e virtuais um com o outro. (Azuma et al., 2001, p. 34)

Para que esses critérios sejam atendidos, é necessário um aparato tecnológico. Magalhães (2010) diz que "a RA é, assim, uma técnica de computação gráfica, que consiste na sobreposição de gráficos sintéticos com a imagem capturada por uma câmara em tempo real." (Magalhães; 2010, p. 24).

Milgran (1995) ainda a define assim, "é a mistura de mundos reais e virtuais em algum ponto da realidade/virtualidade contínua, que conecta ambientes completamente reais a ambientes completamente virtuais." (Milgran; 1995, p. 283)

As primeiras experiências com RA ocorreram em 1957 quando o cinematógrafo Morton Heilig inventou uma cabine chamada Sensorama.

Conforme dito pelo seu criador, "a presente invenção, geralmente, refere-se a um mecanismo de simulação e, mais particularmente, a um aparato para estimular os sentidos de um indivíduo para simular uma experiência real de forma realista." (Heilig, 1962, p. 9). Azuma et al. (2001) diz que a RA pode ser aplicada a todos os sentidos, incluindo audição, toque e olfato, o que também já era previsto nessa invenção. Conforme Heilig (1962) a Sensorama funcionava da seguinte forma:

Um meio de projeção visual de imagem é sustentado pelo alojamento e um recurso ótico é incluído para direcionar imagens do meio de projeção para o capô. Além disto, são fornecidos meios para direcionar uma brisa em direção a este capô, e pelo menos uma substância estimuladora do sentido do olfato é posicionada para ser liberável na brisa em resposta a um sinal de um meio de coordenação adequado. São os efeitos cooperativos da brisa, o odor, as imagens visuais e o som bi natural que estimulam uma sensação desejada nos sentidos de um observador. Para aqueles casos em que um senso de movimento é desejado, meios são fornecidos para induzir pequenas vibrações ou solavancos a simular movimento e, também, simular impactos reais. (Heilig, 1962, p. 9)

Apesar de não ser uma máquina computadorizada, ela já buscava inserir mais elementos na realidade para a imersão do observador e também se baseava em simulações.

Em 1968 o engenheiro elétrico e cientista da computação Ivan Sutherland criou o capacete com display tridimensional - HMD (em inglês head-mounted three dimensional 
display). Esse dispositivo avançava substancialmente na imersão virtual como explica Sutherland, "Nosso objetivo neste projeto foi cercar o usuário com informações tridimensionais. [...]. Podemos exibir objetos ao lado do usuário ou atrás dele, que ficarão visíveis para ele se ele se virar." (Sutherland; 1968, p.757). Devido a restrições tecnológicas da época a estrutura montada tornava impraticável seu uso fora do ambiente de pesquisa.

No início da década de 80 surgiu o primeiro projeto de RA, desenvolvido pela Força Aérea Americana, consistindo em um simulador de cockpit de avião, com visão ótica direta, misturando elementos virtuais com o ambiente físico do usuário (Kirner, 2008). Esse foi um projeto caro e ousado como nos esclarece Kirner:

\begin{abstract}
O simulador Super Cockpit da Força Aérea Americana passou a operar com um capacete de visão óptica, que possibilitava ao piloto uma visão aumentada com informações do avião, como a indicação visual dos mísseis disponíveis para disparo instalados nas asas. Um visor de acrílico permitia a visão direta da cena misturada com a projeção sobreposta das imagens geradas por um display CRT acoplado ao capacete. $O$ custo desse projeto estava na faixa de milhões de dólares. Este é um dos primeiros registros de projetos de Realidade Aumentada. (Kirner; 2008, p. 8)
\end{abstract}

O primeiro artigo científico sobre RA é publicado em 1992 onde o termo foi criado por Thomas Caudell, professor da Universidade do Novo México, que na época trabalhava para um projeto piloto da fabricante Boeing, o artigo de título "Augmented Reality: An Application of Heads-Up Display Technology to Manual Manufacturing Processes" tem como coautor David W. Mizell. Nele era descrito o projeto de desenvolvimento de um óculosdisplay denominado Hudset que através de uma câmera de detecção sobrepunha gráficos gerados por computador no mundo real, facilitando a montagem de complexos circuitos na fabricação de aviões. (Braga; Ulbricht, 2011)

Três anos depois em 1993 é realizado o Workshop on Augmented Reality and Ubiquitous Computing, no MIT, que contou com a presença de diversos pesquisadores entre eles Ronald Azuma e Paul Milgram. Neste mesmo ano foi publicada uma edição especial da revista Communications of the ACM sobre RA, com o título: ComputerAugmented Environments: Back to the Real World.

No ano seguinte em 1994, Paul Milgram et. al. publicaram o artigo Augmented Reality: A Class of Displays on the Reality-Virtuality Continuum, discutindo a Realidade Misturada, abrangendo a RA e a Virtualidade Aumentada (Milgram 1995). 
Um outro marco importante ocorre em 1997 quando o pesquisador Ronald Azuma publica o artigo A Survey of Augmented Reality que desperta um interesse ainda maior na comunidade científica pelo tema.

Em 2000 foi desenvolvido o Sketchup, um software para criação de conteúdo 3D, mais tarde em 2006 ele é adquirido pela empresa Google que cria com isso um dos maiores repositórios gratuitos de objetos 3D.

No ano de 2008 a biblioteca de programação FlarToolkit é liberada, passando a ser usada por desenvolvedores do mundo todo. Com isso, difundindo ainda mais a realidade aumentada, devido a suas criações.

Em 2016 a empresa Niantic juntamente com a Nintendo cria o jogo Pokémon Go em RA voltado para smartphones. Conforme Paavilainen (2017) nele,

Os jogadores são treinadores de Pokémon (monstros de bolso) que pesquisam, capturam, coletam, treinam, evoluem e combatem criaturas Pokémon. O GPS é usado para combinar a localização do mundo real com o mundo virtual. Quando criaturas Pokémon aparecem no mundo virtual, a RA é usada para sobrepor o Pokémon no mundo real visualizado através de uma câmera móvel" (Paavilainen et al., 2017, p. 2493).

Esse jogo em pouco tempo tornou-se um sucesso mundial o que massificou o contato com a RA. Segundo Kari (2017) nos primeiros 80 dias após o lançamento o jogo atingiu a marca de 550 milhões de downloads.

A RA se desenvolveu em paralelo a Realidade Virtual (RV) e, em alguns casos, sua separação e definição se torna difícil pois há uma variação quanto ao nível de virtualização. Um pouco menos divulgada, a Realidade Misturada (RM) se refere a um conjunto mais amplo de interação virtual, Kirner (2011) esclarece que:

Embora o termo realidade misturada seja pouco utilizado, ele define uma interface baseada na sobreposição de informações virtuais geradas por computador (imagens dinâmicas, sons espaciais e sensações hápticas) com o ambiente físico do usuário, percebida através de dispositivos tecnológicos. Quando as informações virtuais são trazidas para o espaço físico do usuário, que usa suas interações naturais, tem-se a realidade aumentada. (Kirner; 2011, p. 15)

Como a RM abarca todo processo de inserção virtual no mundo real podemos considerar conforme Magalhães (2010) que a RA é uma particularização da RM. Pensando nisto Milgram et al. (1995) criaram a escala Reality-Virtuality Continuum mostrada na figura 1 adaptada abaixo: 
Figura 1 - Escala de Milgram adaptada

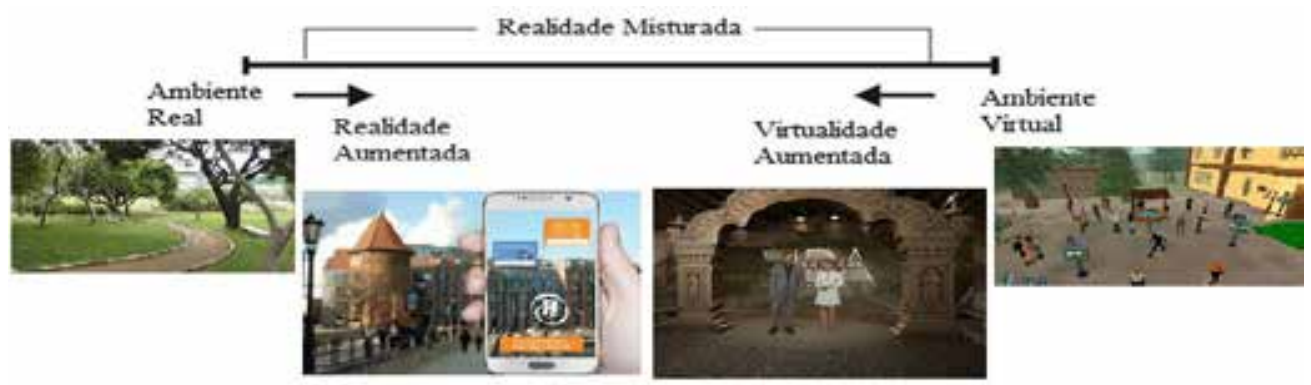

Fonte: Milgram et al. (1995, p. 283) - adaptado pelo autor

Esta escala dividida em quatro partes é assim definida por Milgram (1995):

- Ambiente real: o extremo esquerdo da escala é a visão de um ambiente formada apenas por objetos reais.

- $\quad$ Realidade Aumentada: o mundo real é o ambiente principal e é aumentado através de dados gerados por computador.

- Virtualidade Aumentada: o mundo virtual é o ambiente principal e é aumentado por objetos do mundo real.

- $\quad$ Ambiente virtual: é um ambiente completamente formado por objetos virtuais. A realidade é completamente substituída por um ambiente totalmente sintético.

Portanto, diante desta divisão é possível criar uma nítida delimitação do que de fato compreende a RA. Para que isto fique ainda mais claro podemos nos valer da comparação de Kirner (2006):

Realidade virtual trabalha unicamente com o mundo virtual; transfere o usuário para o ambiente virtual; e prioriza as características de interação do usuário. Realidade aumentada possui um mecanismo para combinar o mundo real com o mundo virtual; mantém o senso de presença do usuário no mundo real; e enfatiza a qualidade das imagens e a interação do usuário. (Kirner; Tori, 2006, p. 22)

Apesar dos conceitos originais se manterem, a evolução computacional provocou muitas mudanças na RA, computadores mais potentes e dispositivos como smartphones, tablets e handhelds tornam a RA mais acessível e presente no dia a dia. Grubert et al. (2016) diz que os sistemas de RA existentes podem ser divididos em sistemas de RA estacionários ou de mesa (computadores) e sistemas de RA móveis (smartphones entre outros).

“A Educação pode ser vista como um processo de descoberta, exploração e de observação, além de eterna construção do conhecimento" (Braga, 2001, p. 6). Estes três pontos citados por Braga (2001), descoberta, exploração e observação estão em perfeita 
sintonia com a RA, pois ela possibilita realizar explorações que seriam inviáveis no mundo real, tendo uma posição de observação totalmente maleável, onde o explorador pode analisar pequenos detalhes ou mesmo se colocar dentro do objeto observado, tudo isto propiciando novas descobertas e conhecimento ao observador.

Dentre os diversos campos de pesquisa da RA a sua aplicação à educação se destaca, seu potencial criativo permite que ela seja utilizada de diversas maneiras e em todas as áreas do conhecimento. Bower et al. (2014), apontou em seu estudo citando alguns outros autores as pedagogias que poderiam ser apoiadas pela RA:

- $\quad$ Aprendizagem construtivista - usando RA de uma maneira que incentive os alunos a se envolver em um nível mais profundo com as tarefas, conceitos e recursos que estão sendo estudados através do uso de sobreposições de informações, os alunos podem fazer conexões profundas e duradouras em sua base de conhecimentos (Kerawalla, Luckin, Seljeflot e Woolard, 2006).

- $\quad$ Aprendizagem situada - a aprendizagem autêntica e contextualizada é possibilitada pela incorporação de experiências educacionais no ambiente do mundo real e pela inserção do mundo real na sala de aula (Chen \& Tsai, 2012; Dede, 2009; Dunleavy et al., 2009; Rasimah et al., 2011).

- $\quad$ Aprendizagem baseada em jogos - Os sistemas de RA podem ser usados para facilitar a aprendizagem imersiva baseada em jogos, criando uma narrativa digital, colocando os alunos em um papel, fornecendo recursos autênticos e incorporando informações contextualmente relevantes (por exemplo, Dunleavy et al., 2009; Klopfer \& Squire, 2008; Squire \& Jan, 2007).

- Aprendizado baseado em perguntas - oferecendo um meio de coletar eletronicamente dados para análises futuras (por exemplo, Dunleavy et al., 2009) e fornecer modelos virtuais situados em um contexto do mundo real.

\section{O ensino de história}

Os professores de História independentemente do nível escolar que atuem, enfrentam dificuldades para sensibilizar os estudantes a compreenderem algo que, à primeira vista, pode parecer simples, mas que possui alta complexidade. "Compreender que a História ensinada na escola não corresponde a mera transposição didatizada dos 
elementos constituídos no âmbito da historiografia não é tarefa fácil." (Miranda, 2009, p.55)

O ambiente escolar é um lugar onde deve ser permitido ao aluno vivenciar diversas interações sociais, políticas e culturais, portanto não basta que a disciplina de História seja oferecida como exposição de recortes de dados históricos, mas sim, para gerar no estudante uma consciência histórica. Boschi (2007) nos diz sobre a função da História:

\footnotetext{
Trocando em miúdos, a História serve para que o homem conheça a si mesmo assim como suas afinidades e diferenças em relação a outros. Saber quem somos permite definir para onde vamos. Quem sou eu? De onde vim? Para onde vou? Perguntas como essa são uma constante na história da humanidade. Por mais sem sentido que pareçam, tais indagações traduzem a necessidade que temos de nos explicar, nos situar, nos (re)conhecer e em decorrência, como seres sociais. (Boschi, 2007, p. 12)
}

A História nos auxilia a nos reconhecermos, seja como grupo ou como indivíduos, portanto seu ensino deve estar intimamente ligado a esta formação humanística e na medida em que nos compreendemos e o mundo que nos cerca, construímos um saber crítico e lúcido desprovido de preconceitos em uma aprendizagem histórica significativa. Guimarães (2014) nos diz que a história "permite que as experiências sociais sejam vistas como um constante processo de transformação - um processo que assume formas muito diferenciadas e que é produto das ações dos próprios homens”. (Guimarães, 2014, p. 41)

Diante de tamanha relevância da História cabe nos perguntar, como ela é feita? E igualmente pertinente, como ela é transmitida? Aquilo que fazemos cotidianamente tornase a história deixando traços de nossa passagem pelo tempo. "A história como experiência humana torna-se objeto de investigação do historiador, que realiza o levantamento das fontes históricas, analisa-as, dialoga com as teorias e com os outros achados produzidos na esfera social e os transforma em conhecimento." (Guimarães, 2014, p. 42)

Enquanto realiza seu trabalho de vasculhar arquivos, localizar documentos, analisar obras e construções históricas, o historiador não age de forma neutra, ou seja, os fatos são analisados por uma perspectiva, a sua. Jenkins (2001) diz que os historiadores em primeiro lugar no seu trabalho levam a si mesmos, seus valores, posições e perspectivas ideológicas, em segundo lugar levam seus pressupostos epistemológicos, em terceiro lugar eles têm métodos e rotinas, em quarto lugar o historiador de fato transforma vestígios do passado em pensamento concreto e em quinto lugar o historiador depois de sua pesquisa precisa 
escreve-la e novamente os fatores epistemológicos, metodológicos e ideológicos entram em ação.

A história que recebemos traz consigo a visão do seu pesquisador, mesmo que seja muito debatido o quão distante dos fatos deve estar o historiador, suas conclusões sempre terão uma parcela de sua identidade.

[...] qualquer coisa que ele faça, o espírito público do seu tempo reage sobre ele. [... ] Sua maneira de considerar a história é imposta ao historiador pelo seu tempo. O ponto de vista no qual se situa não é determinado, como nas ciências, pelo estado do desenvolvimento dos conhecimentos, mas pelo estado de civilização do público ao qual se dirige e ao qual ele mesmo pertence. [...]. Cada época refaz sua história, transpõe-na, de certa forma, em um tom que lhe é apropriado. [...]. O historiador é dominado, sem perceber, pelas ideias religiosas, filosóficas, políticas que circulam ao seu redor (Pirenne 1897, p. 51-52).

A História é viva e, portanto, muda em forma com relação aos critérios de prova e corroboração, causa e efeito, conceitos, teorias e continuidade. Guimarães (2014) separa a História ensinada em duas vertentes, a História Tradicional e a nova História.

A História tradicional dominou o século XIX, onde na Europa ela passou a ser considerada uma ciência e tornou-se disciplina escolar. Sobre ela Guimarães (2014) diz:

A história tradicional ou positivista privilegiava como fontes os documentos escritos, oficiais e não oficiais (leis, livros), e também os sítios arqueológicos, as edificações e os objetos de coleção e museus, como moedas e selos. Os sujeitos da História tradicional eram grandes personalidades políticas, religiosas e militares: reis, líderes religiosos, generais, grandes proprietários. Eram grandes atores individuais, heróis que geralmente apareciam como construtores da história. (Guimarães, 2014, p.44)

O conceito de História nova teve como berço a França já no século XX, tendo como uma obra de referência a coleção de ensaios La nouvelle histoire de Le Goff, renomado historiador francês. Também na França surge a École des Annales que aparece na contraposição a Historiografia Tradicional, que buscava segundo Oliveira (2014):

Uma história que se investiga e se narra a partir de aspectos mais gerais e duradouros. Não mais narração da história diplomática e dos eventos que possuíam um caráter investigativo mais específico e limitado, sem dialogar com outras ciências e, tampouco, sem dialogar com outras forças de ação social que conjuntamente construíam a história total que, será agora, a bandeira da École dês Annales. (Oliveira, 2014, p. 128)

A nova História como vem nos esclarecer Burke, "começou a se interessar por virtualmente toda a vida humana [...]. O que era previamente considerado imutável é agora encarado como uma construção cultural, sujeita a variações, tanto no tempo quanto no espaço.” (Burke, 1992, p. 11). Na nova história os fatos devem ser observados em uma 
perspectiva social e cultural, ela inverte o ângulo de observação, se antes eram considerados apenas os grandes nomes de políticos e autoridades, agora interessa a visão do homem comum e seu coletivo social.

A nova História continua sendo construída, Burke (1992) nos diz que:

Embora a expansão do universo do historiador e o diálogo recente com outras disciplinas, desde a geografia até a teoria literária, certamente devam ser benvindos, esses desenvolvimentos têm seu preço. A disciplina da história está atualmente mais fragmentada que nunca. Os historiadores econômicos são capazes de falar a linguagem dos economistas; os historiadores intelectuais, a linguagem dos filósofos; e os historiadores sociais, os dialetos dos sociólogos e dos antropólogos sociais, mas estes grupos de historiadores estão descobrindo ser cada vez mais difícil falar um com o outro. Teremos de suportar esta situação ou há uma esperança de síntese? (Burke, 1992, p. 12)

O próprio Burke (1992) acredita que ainda há um longo caminho a percorrer para alcançar uma História que integre elementos tanto da História tradicional quanto da nova, mas que passos importantes já foram dados na busca de um ponto central de forma que elas se inter-relacionem.

A História além de documentada deve ser ensinada, e neste sentido Guimarães (2014) diz que o currículo de História sofre pressões políticas pois a que se definir o que da cultura, da memória e da experiência humana ensinar, o que é significativo, válido e importante da História mundial e do Brasil. A História como disciplina é muito grande e não seria possível ensiná-la em sua totalidade, portanto, a história que é ensinada trata-se de uma seleção, um recorte temporal, e por isto pode vir carregada de perspectivas políticas. "Um currículo de História é sempre processo e produto de concepções, visões, interpretações, escolhas, de alguém ou de algum grupo em determinados lugares, tempos, circunstâncias." (Guimarães, 2014, 61)

Como dito por Prats(2006) a finalidade do estudo de História é facilitar a compreensão do presente, preparar os alunos para a vida adulta, despertar o interesse pelo passado, potencializar nas crianças e adolescentes um sentido de identidade, ajudar os alunos na compreensão de suas próprias raízes culturais e da herança comum, contribuir para o conhecimento e a compreensão de outros países e culturas do mundo atual, contribuir para o desenvolvimento das faculdades mentais por meio de um estudo disciplinado, introduzir os alunos em um conhecimento e no domínio de uma metodologia rigorosa, própria dos historiadores e enriquecer outras áreas do currículo. 
Para atingir esses objetivos diversas técnicas podem ser aplicadas e existem várias metodologias de ensino desde as mais tradicionais até algumas de vanguarda. Dentre essas possibilidades, a aplicação de RA também vem sendo utilizada e testada, sua capacidade ilustrativa e sensorial permite o seu uso na disciplina de História de diversas maneiras, seja apresentando objetos históricos em tamanho real, reconstrução de ambientes históricos, enriquecimento de monumentos com dados ou acesso a imagens e sons que remetem a momentos históricos relevantes.

\section{A RA aplicada ao ensino de história}

O interesse em pesquisas de RA aplicadas à educação acompanha a evolução de dispositivos móveis, apesar de não estar atrelada a eles, o ganho em mobilidade obtido facilita a sua aplicação. Lee (2012) diz que:

A RA foi aplicada experimentalmente em ambientes escolares e empresariais, embora não tanto quanto os métodos clássicos de educação e treinamento nas últimas duas décadas. Além disso, agora as tecnologias que tornam possível a RA estão mais poderosas e compactas do que nunca, o suficiente para oferecer experiências de RA não apenas às corporações, mas também a locais acadêmicos por meio de computadores pessoais e dispositivos móveis, várias abordagens educacionais com tecnologia de RA são mais viáveis. Além disso, dispositivos móveis sem fio, como smartphones, tablets, PCs e outras inovações eletrônicas, estão cada vez mais introduzindo a RA no espaço móvel, onde os aplicativos oferecem uma grande promessa, especialmente em educação e treinamento. (Lee, 2012, p. 14)

Os resultados dos estudos realizados sobre a aplicação da RA na educação demonstram que ela afeta principalmente a motivação dos alunos e a aprendizagem de conteúdos. Segundo Billinghurst e Duenser (2012), “os resultados mostram que o alto nível de interatividade da RA melhora o aprendizado, principalmente para os alunos que aprendem por meio de métodos cinestésicos, visuais e outros não baseados em texto." (Billinghurst e Duenser, 2012, p. 62)

A RA fornece um recurso sensorial que auxilia de forma particular aqueles alunos que enfrentam alguma dificuldade em compreender conteúdos expostos apenas em livros ou por meio da fala, mas que melhoram seu desempenho quando utilizam meios visuais, sonoros ou táteis. Para Dunleavy, Dede e Mitchell (2009) “o componente físico inerente a RA não é apenas motivador, mas também oferece oportunidades únicas para criar ambientes de aprendizado autênticos e inovadores, que utilizam itens reais e digitais em um espaço físico externo." (Dunleavy, Dede e Mitchell, 2009, p. 14) 
Dentre as diversas possibilidades de aplicação da RA na educação está também o ensino de História. Esta aplicação específica é o objeto deste estudo, portanto a destacaremos a seguir.

Em 2018 foi desenvolvido um estudo no Museu Histórico Nacional com a inserção de RA na exposição de veículos antigos, os visitantes poderiam baixar o aplicativo e acessar as projeções que traziam dados adicionais e também modelos dos veículos que poderiam inclusive ser vistos em seu interior. Em seu estudo sobre está aplicação Marçal (2018, p.79) diz que "a tecnologia não se sobrepõe ao acervo, se apresenta como uma nova camada narrativa, a exemplo do áudio-guia."

A pesquisadora analisou apenas os resultados da utilização de RA, não tendo participação direta no desenvolvimento da tecnologia nem de sua aplicação. Ela constatou que o público continuava interessado em ver os modelos físicos, mas a RA fornecia um material complementar que ajudava ao observador a entender o contexto onde aqueles veículos se encontravam.

Em um estudo desenvolvido na Indonésia os pesquisadores criaram modelos em 3D de templos históricos e culturalmente relevantes de seu país, mas que eram de difícil acesso pelos estudantes, assim por meio destas representações os alunos puderam ter contato com sua arquitetura, detalhes de sua ornamentação e perfil histórico. Os pesquisadores Utami e Lutfi (2019) concluíram que o desempenho avaliativo dos alunos do ensino médio que utilizaram a RA foi melhor em comparação a turma que não utilizou esse recurso.

Costa e Cruz (2015) em seu estudo reconstruíram o Fórum antigo de Roma em 3D e os alunos do $3^{\circ}$ ano do ensino médio puderam manipular este modelo observando todos os seus detalhes e posteriormente responderam a um questionário sobre o local. O estudo destacou que o interesse dos alunos em aprender sobre o edifício aumentou em comparação a aprendizagem apenas com modelos 2D em livros. O estudo limitou-se a apenas um modelo em 3D, o que limitou sua observação durante a utilização pelos alunos.

No Equador em um estudo publicado em 2018 os pesquisadores Paredes-Velasteguí, et al. (2018), aplicaram a RA como um recurso adicional aliado ao próprio livro didático de história da escola, que receberam adesivos em suas páginas como marcadores fiduciais. $\mathrm{O}$ trabalho foi realizado no $2^{\circ}$ ano do ensino médio daquele país e continha representações em 3D referentes ao final do Império Romano, a arte no cristianismo e a arte islâmica. 
Durante três meses enquanto uma turma permaneceu utilizando apenas o livro didático outra usou este recurso, ao final do experimento a turma que teve acesso a RA apresentou notas $17 \%$ maiores do que as do grupo de controle e $86 \%$ dos alunos aprovaram a nova ferramenta.

Os pesquisadores Hsu, Chen, Wu (2015) utilizaram a RA no ensino da história da computação utilizando figuras históricas desta área. Enquanto estudavam utilizando seus livros os estudantes puderam usar tablets para digitalizar os personagens históricos e acessar vídeos que contavam sua trajetória, ao todo foram selecionadas treze pessoas. Os resultados apontaram que os alunos que acessaram a RA ficaram mais motivados e interessados e que os vídeos os ajudaram a compreender melhor o contexto e a relevância histórica de cada indivíduo na história da computação.

Os pesquisadores Blanco-Fernandéz et al. (2014) na Espanha usaram a RA para revisitar grandes batalhas da humanidade por um outro olhar, mais próximo. O período escolhido foi o mundo clássico, especificamente abordando as guerras helênicas com imagens em três dimensões de soldados, templos, armaduras e inclusive mapas mostrando a movimentação da batalha. Na proposta os pesquisadores esperavam que os usuários interagissem de forma constante, mais o estudo indicou que apesar da melhora nesse aspecto não houve uma interação tão efetiva entre indivíduos que não se conheciam previamente.

Os estudantes demonstram a partir de questionários aplicados comparados com avaliações prévias compreender melhor os aspectos das guerras antigas depois da utilizam da RA.

Em um estudo desenvolvido em Chipre foi desenvolvido um aplicativo em RA para criar nos alunos empatia histórica, para que eles criassem relação entre passado e presente entendendo como fatos ocorridos a muito tempo influenciam a vida atual. O aplicativo funcionava baseado em geolocalização, os alunos foram convidados para uma visita a um sítio arqueológico da era neolítica e durante o passeio ao atingirem determinadas coordenadas geográficas os estudantes tinham acesso a vídeos, textos imagens e páginas da web que complementavam a experiência.

O estudo encontrou desafios principalmente por ser feito ao ar livre. Os estudantes tiveram dificuldade de visualizar as informações devido a incidência da luz solar e ao procurar um local mais escuro eles saiam das coordenadas. A extensão do sítio 
arqueológico e a presença de turistas causou fadiga nos alunos. Há também o risco de acidentes, os discentes estão se locomovendo e ao mesmo tempo olhando para o tablet, em ambientes acidentados isso pode ser perigoso para a integridade física.

Os pesquisadores Efstathiou, Kyza e Georgiou (2018) concluíram com base na investigação realizada que o projeto contribuiu para a empatia histórica onde os estudantes compreenderam melhor o impacto de fatos pretéritos nos dias atuais o que foi mensurado com base em entrevistas.

Em Viena na Áustria os estudantes foram convidados a conhecerem mais sobre a caça às bruxas realizada pela igreja católica no início da era moderna. Foi utilizado o software de RA gratuito Aurasma, e foram espalhados diversos marcadores fiduciais por toda a sala de aula. Os estudantes usando seus smartphones se aproximavam dos marcadores que disparavam animações com mais informações sobre o tema.

Os resultados apontados por Buchner e Zumbach (2018) mostram que do pré-teste sobre o tema para o pós-teste houve um crescimento de pontuação muito forte de $31 \%$ para $66 \%$. É preciso destacar que a amostra era pequena e por isso pode gerar algumas distorções nos resultados.

Silva et al utilizaram em sua pesquisa o jogo Arcos, uma ferramenta em RA para auxílio no ensino de história através de um jogo. A solução envolve dois pilares, sendo o primeiro deles, um jogo de realidade aumentada para dispositivos móveis. O segundo pilar consiste em uma plataforma web em que o professor personaliza o jogo para se adequar a sua aula. O objetivo da solução é despertar o interesse do aluno sobre a História de sua cidade, nesse caso Quixadá.

Em um tabuleiro virtual os alunos movimentam um personagem de forma colaborativa pelas casas, em cada uma delas são liberadas dicas que serão usadas para responder a pergunta final e ganhar o jogo.

O tabuleiro conta com três tipos de casas: Casas de dicas chamadas de casas dinâmicas pois os professores podem alterá-las na plataforma web para criar seus próprios jogos, contando a História que eles quiserem, onde através dessas dicas os alunos devem solucionar sobre o que é essa História respondendo uma pergunta de múltipla escolha ao final do jogo, que chamamos de casa de palpite. Há também as casas de pergunta e resposta que são as casas fixas padrões do jogo e não podem ser alteradas pelo professor. Elas são importantes pois são elas que vão garantir o ensino básico de História local para 
os alunos que irão jogar, pois ao cair nelas os jogadores liberam locais históricos icônicos de Quixadá e aprendem sobre eles respondendo perguntas geradas pelo sistema, além de visualizar o local em 3D projetado no tabuleiro.

\section{CONSIDERAÇÕES FINAIS}

A disciplina de História carrega consigo a responsabilidade de formação do estudante com capacidade crítica de compreender o mundo que o cerca e também de intervir nela. É próprio dessa área de ensino propiciar a emancipação civilizatória do homem, não se trata apenas de ensinar fatos, datas e personagens históricos, mas sim, entender como tudo isso em um fluxo temporal constante afeta a atualidade.

Ferramentas tecnológicas como a RA contribuem para o ensino de História principalmente por aproximar o discente do objeto histórico analisado. Em muitos casos os alunos veem apenas imagens presentes nos livros que não apresentam detalhes, características essenciais ou mesmo a grandiosidade de uma construção. A visualização em 3 dimensões permite um mergulho nas particularidades de cada obra e favorecem uma melhor compreensão.

Por meio da revisão bibliográfica apresentada nesse estudo foi possível observarmos que existem várias iniciativas de utilização da RA no ensino de história com os mais variados modelos. Em geral esses estudos obtiveram como resultado melhora na aprendizagem dos estudantes, maior motivação, engajamento e interação entre os participantes, o que indica que a RA pode ser uma poderosa aliada na docência de História.

A fim de contribuir com esses estudos esperamos em trabalhos futuros desenvolver um aplicativo de RA para apoio como ferramenta pedagógica no ensino de História no Ensino Médio. Esse aplicativo usará como marcadores fiduciais imagens dos próprios livros usados pelos estudantes em sala de aula e exibirá imagens em 3 dimensões e vídeos com maiores informações sobre os temas estudados. Investigaremos se de fato há melhora na aprendizagem e na motivação dos discentes como vem sendo apontado pelos estudos na área. 


\section{REFERÊNCIAS}

AZUMA, Ronald et al. Recent advances in augmented reality. IEEE computer graphics and applications, v. 21, n. 6, 2001, p. 34-47.

BILLINGHURST, Mark; DUENSER, Andreas. Augmented reality in the classroom. Computer, v. 45, n. 7, 2012, p. 56-63.

BLANCO-FERNÁNDEZ, Yolanda et al. Reenact: A step forward in immersive learning about human history by augmented reality, role playing and social networking. Expert Systems with Applications, v. 41, n. 10, 2014, p. 4811-4828.

BOSCHI, Caio César. Porque estudar história?. São Paulo: Editora Ática, 2007.

BOTELHO, L. L. R., de Almeida Cunha, C. C., \& Macedo, M. O método da revisão integrativa nos estudos organizacionais. Gestão e sociedade, v. 5, n. 11, 2011, p. 121-136.

BOWER, Matt et al. Augmented reality in education-cases, places and potentials. Educational Media International, v. 51, n. 1, 2014, p. 1-15.

BRAGA, Mariluci. Realidade virtual e educação. Revista de biologia e ciências da terra, v. 1, n. 1, 2001, p. 0.

BRAGA, Marta Cristina Goulart; ULBRICHT, Vania Ribas. Revisão sistemática quantitativa: identificação das teorias cognitivas que apoiam o design de interface no uso da realidade aumentada na aprendizagem online. Revista EducaOnline, v. 5, n. 1, 2011, p. 84-100.

BUCHNER, Josef; ZUMBACH, Jörg. Promoting intrinsic motivation with a mobile augmented reality learning environment. International Association for Development of the Information Society, 2018.

BURKE, Peter. A nova história, seu passado e seu futuro. A escrita da história: novas perspectivas. São Paulo: UNESP, 1992.

COSTA, Maria Alcide; CRUZ, Sónia. A utilização da realidade aumentada para aprender história: um estudo com alunos do 3. ${ }^{\circ}$ CEB. Challenges, p. 119-135, 2015

DUNLEAVY, Matt; DEDE, Chris; MITCHELL, Rebecca. Affordances and limitations of immersive participatory augmented reality simulations for teaching and learning. Journal of science Education and Technology, v. 18, n. 1, 2009, p. 7-22.

DUVAL, Raymond. Registros de representação semiótica e função cognitiva do pensamento. Anais de Didática e Ciências Cognitivas, Estrasburgo, v. 5, 1993, p. 35-65.

EFSTATHIOU, Irene; KYZA, Eleni A.; GEORGIOU, Yiannis. An inquiry-based augmented reality mobile learning approach to fostering primary school students' historical reasoning in non-formal settings. Interactive Learning Environments, v. 26, n. 1, 2018, p. 22-41. 
GIL, A. C. Como elaborar projetos de pesquisa. São Paulo: Atlas, 2002.

GRUBERT, Jens et al. Towards pervasive augmented reality: context-awareness in augmented reality. IEEE transactions on visualization and computer graphics, v. 23, n. 6 , 2016, p. 1706-1724.

GUIMARÃES, Selva. Didática e prática de ensino de história. Papirus Editora, 2014.

HEILIG, Morton L. Sensorama simulator. U.S. Patent, 1962.

HSU, Ching-Yin; CHEN, Mei-Wen; WU, Cheng-Chih. Teaching high school computer science with videos of historical figures--an augmented reality approach. In: 2015 International conference on learning and teaching in computing and engineering. IEEE, 2015. p. 22-25. IBGE. Pesquisa nacional por amostra de domicílios. Rio de Janeiro: IBGE,2018.

JENKINS, Keith. O que é história. São Paulo: Contexto, 2001.

KARI, Tuomas; ARJORANTA, Jonne; SALO, Markus. Tipos de mudança de comportamento com o Pokémon GO. In: Anais da $\mathbf{1 2}^{\mathrm{a}}$ conferência internacional sobre os fundamentos dos jogos digitais . 2017. p. 1-10.

KIRNER, Claudio. Evoluçao da realidade virtual no brasil. In: $\mathrm{X}$ symposium on virtual and augmented reality. 2008. p. 1-11.

KIRNER, Claudio; KIRNER, Tereza Gonçalves. Evolução e tendências da realidade virtual e da realidade aumentada. Realidade virtual e aumentada: aplicações e tendências. Cap, v. 1, 2011, p. 10-25.

KIRNER, Cláudio; TORI, Romero. Fundamentos de realidade aumentada. Fundamentos e Tecnologia de Realidade Virtual e Aumentada, v. 1, p. 22-38, 2006.

LEE, Kangdon. Augmented reality in education and training. TechTrends, v. 56, n. 2, 2012, p. 13-21.

MAGALHÃES, Paulo Sérgio Teixeira de. Realidade aumentada aplicada ao processo de ensino/aprendizagem. Estudo de Caso. Dissertação de Mestrado. Instituto Superior de Engenharia do Porto: Portugal, 2010.

MARÇAL, Alessandra de Oliveira. A realidade aumentada como ferramenta de mediação: análise crítica de sua aplicação no Museu Histórico Nacional. Rio de Janeiro: UNIRIO/MAST, 2018.

MARTINS, Viviane Lima. Tecnologia de Informação e Comunicação (TIC) e educação. Revista Científica Intr@ ciência, v. 13, p. 1, 2017. 
MENDONÇA, Helena A. Construção de jogos e uso de realidade aumentada em espaços de criação digital na educação básica. Metodologias ativas para uma educação inovadora. Porto Alegre: Penso, 2018.

MERCADO, Luís Paulo Leopoldo. Novas tecnologias na educação: reflexões sobre a prática. Alagoas: UFAL, 2002.

MILGRAM, Paul et al. Augmented reality: a class of displays on the reality-virtuality continuum. In: Telemanipulator and telepresence technologies. International Society for Optics and Photonics, 1995. p. 282-292.

MIRANDA, Sônia Regina. História, memória e formação de professores: desafios e perspectivas para o cotidiano de uma didática da história. Campinas: Editora Alínea, 2009.

MORÁN, José. Mudando a educação com metodologias ativas. Coleção mídias contemporâneas. Convergências midiáticas, educação e cidadania: aproximações jovens, v. 2, n. 1, 2015, p. 15-33.

OLIVEIRA, Ana Fernanda Inocente. O sentido da história para a École des Annales. Araraquara/ SP: CNPQ, 2014.

PAAVILAINEN, Janne et al. The Pokémon GO experience: a location-based augmented reality mobile game goes mainstream. In: Proceedings of the $2017 \mathrm{CHI}$ conference on human factors in computing systems. 2017. p. 2493-2498.

PAREDES-VELASTEGUÍ, D. et al. Augmented reality implementation as reinforcement tool for public textbooks education in Ecuador. In: 2018 IEEE global engineering education conference (EDUCON). IEEE, 2018. p. 1243-1250.

PIRENNE, Henri. Une polémique historique en Allemagne. Revue historique, v. 64, n. 1, p. 50-57, 1897.

PRATS, Joaquín. Ensinar história no contexto das ciências sociais: princípios básicos. Educar em revista, 2006, p. 191-218.

SANTOS, Fábio Maurício Fonseca; ALVES, André Luiz; DE MAGALHÃES PORTO, Cristiane. Educação e tecnologias. Revista Científica da FASETE, 2018, p. 44- 61.

SILVA, Daniel Oliveira et al. Solução educacional para auxiliar as aulas de história local do ensino fundamental II.

SUTHERLAND, Ivan E. A head-mounted three dimensional display. In: Proceedings of the december 9-11, 1968, fall joint computer conference, part I. 1968. p. 757-764.

TEZANI, Thaís Cristina Rodrigues. A educação escolar no contexto das Tecnologias da Informação e da Comunicação: desafios e possibilidades para a prática pedagógica curricular. Revista Faac, v. 1, n. 1, 2011, p. 35-45. 
TORI, R. Educação sem distancia: as tecnologias interativas na redução de distancias em ensino aprendizagem. São Paulo: editora SENAC, 2010.

UTAMI, Indah Wahyu Puji; LUTFI, Ismail. Effectivity of augmented reality as media for history learning. International Journal of Emerging Technologies in Learning, v. 14, n. 16, 2019.

Recebido em: 12/09/2020

Parecer em: 29/12/2020

Aprovado em: 12/02/2020 